\title{
Digital Literacy and its Acquisition by Teachers and Principals at Educational Workplaces
}

\author{
Ahmad A. S. Tabieh, Mohammad Hamzeh, Basel Kh. S. Abu-Foudeh, \\ Niveen Jarrar, Sahar Al-Manaseer, Aysha Al-Shawabkeh and Rania Seikaly \\ Middle East University, Amman, Jordan \\ https://orcid.org/0000-0001-6762-6313 \\ https://orcid.org/0000-0002-1021-2336 \\ https://orcid.org/0000-0001-7988-490X \\ https://orcid.org/0000-0002-3136-0274 \\ https://orcid.org/0000-0002-4865-6573 \\ https://orcid.org/0000-0002-3774-4156 \\ https://orcid.org/0000-0001-6258-7386
}

\begin{abstract}
This study investigates the digital literacy skills among workers in the educational workplace in Jordon. A convenience sample of 139 teachers and 73 administrators spread over 173 public schools and 39 private schools was selected. The study followed mixed quantitative and qualitative methods. Data were collected using two instruments: a semi structured interview to investigate and monitor the digital literacy skills; a questionnaire to measure the availability degree of the digital literacy skills and the significant differences in the availability degree due to the job title and the workplace. In this study, four areas represent digital literacy skills: functional skills, information skills, digital competency in the educational process and digital competency in empowering learners. The availability degree of digital skills is medium in general and statistically significantly higher in administrators than in teachers. The results showed that private sector workers have better digital literacy skills than their public sector peers. Finally, the study concluded that functional and information skills increase digital competency in the educational learning process and empower learners.
\end{abstract}

Keywords: digital competence; digital functional skills; digital informational skills; digital literacy

\section{Introduction}

Education has become the most appropriate tool to reflect the requirements of the market economy and the new society. The change in education foundations accompanies a global process of reorienting education results towards the globalised society and digital economy. Thus, the competitive employee must know the details of his profession, know how to work in a team, be social, be stable 
in challenging situations, perform tasks and master many competencies necessary for professional work, especially digital literacy acquisition. More focus should be placed on digital literacy, as digital trends are growing and overlapping with the cultural and educational world, in terms of cultural convergence, information technologies and the impact on information and communication technologies (ICTs), on new forms of communication. Therefore, digital literacy is concerned with understanding and appropriately using modern ICTs and their functions in work or daily life, represented by different teaching resources that teachers use, such as e-textbooks, digital educational resources and the Internet, and the use of various technologies while conducting lessons, such as distance learning, elearning, open online courses and open educational resources (Yelubay et al., 2020).

Digital literacy is highly important because digital technology is an integral part of modern society, promotes economic development, and helps face the challenges and perspectives of modern digital society. Moreover, digital literacy reflects the extent of digital technology use and focuses on the effort made to eradicate technological illiteracy (Bosler et al., 2019). It also contributes to developing new educational capabilities that stimulate social change through various digital practices for future youth (Ehret \& Čiklovan, 2020).

One of the distinguishing features of digital literacy in education is dealing with large amounts of information, as digitisation is a technical, cultural and economic reality. Simultaneously, an organisational fact is that as the amount of data produced by humans and machines grows dramatically, the material costs related to energy storage decrease. Furthermore, treat them (Bortolazzo, 2020).

The digital age sheds light on the educational phenomenon, as the current generations are advocates of major changes taking place in the world: globalisation, internationalisation and digitisation. These phenomena increasingly affect educational systems, which led to changing the traditional teacher-based and student-centred educational model into a widespread educational model for digital technologies. This shift is related to future changes and the nature of work and requires new competencies. Digital literacy in education, training and learning provides various opportunities and challenges to recreate the curriculum architecture according to the real needs in the labour market (Catalano, 2019).

This study evaluates the importance of digital literacy to keep pace with globalisation and technological developments among the emerging generations. Therefore, scientific research continues to reveal the skills of digital literacy and the degree of its availability among teachers and administrators of the Ministry of Education in Jordan. Yelubay et al., (2020) showed that teachers lack digital literacy and are incompetent in using digital technology. Moreover, Gabriella, (2020) confirmed the attempts to implement or enhance digital literacy in basic education networks are weak. 
Moreover, this study reveals digital literacy skills and the degree of their availability among teachers and administrators of the Ministry of Education in the government sector and public schools. In the statistical report for the academic year 2018/2019 by the Jordanian Ministry of Education, the number of teachers and administrators working in the ministry across various governorates was 87,734 and 17,643, respectively (Al-Omari, 2019).

This current study is practically important because it is a recent study in the digital literacy field. In this way, it enriches the Arab research and calls for researches to pay more attention to this subject from different angles so that more comprehensive studies are conducted, contributing to supporting theoretical literature in general and Jordanian Arab research in particular.

This study provides a list of digital literacy skills, which reveals the strengths and weaknesses of their degree of availability in teachers and administrators of the Jordanian Ministry of Education. Therefore, it benefits the experts, researchers, those concerned with digital literacy and those in charge of designing training programs for teachers and administrators of the Ministry of Education on digital literacy skills.

A report by the UNICEF, (2017) explained that one-third of the world's Internet users are children and adolescents and the group that accesses the Internet the most are young people (15-24 years old). This conclusion indicates the ease of connection to the Internet, especially with the widespread ownership of smartphones among school students and their involvement in digital literacy to a large extent (Hanafy, 2019). Thus, digital literacy has become one of the features of education in knowledge societies, where teachers and administrators of the Ministry of Education are involved.

The current study investigates one of the top research issues as part of scientific research priorities in the education sector in recent years (2011-2020) (The Higher Council for Science and Technology, 2010). Hence, more studies are warranted on digital literacy skills and their availability among teachers and administrators of the Ministry of Education in Jordan.

\section{Literature Review}

Digital literacy skills are defined as open and dynamic processes dependent on interactive communication, which require knowledge to use ICTs, especially the Internet, and contribute to a new understanding of cultural creativity (Kumar \& Bhushan, 2020). Digital literacy is related to an individual's ability and knowledge to access and use the technology needed to live, learn, and work in a society where communication and accessing information are the basis of functioning efficiently (Al-Omari, 2019).

A digitally literate individual must be able to use both cognitive and technical skills. Cognitive skills are brain-based skills essential in acquiring, manipulating and reasoning with data. Teachers at the Ministry of Education in Jordan must 
have the fundamental digital skills to conduct engaging classroom sessions that maximise students' learning abilities (Levy, 2018).

At an educational institute, a digitally literate teacher and administrator must understand the importance of acquiring and using the correct information efficiently to empower students so that they can create and produce innovative work, evaluate and justify a situation, analyse and connect ideas, apply and use knowledge learned, understand and explain concepts and recall facts.

While acquiring all the essentials from the world of digits, teachers and administrators must be cautious about using the correct information. They have a big responsibility to direct their students' minds to a safe and rich path (Bhaumik, 2020).

Another fundamentally important point for teachers and administrators is to understand that technology has an expiry date. They must choose devices, platforms and software programs wisely to avoid continuous change over short periods. Although change and staying up to date are essential in reaching goals and exceeding expectations for an institution, selecting reliable and well-tried digital tools is the key to succeeding, which will provide a solid foundation to any digital tool in place (Pettersson, 2018).

The administrative section in any educational institute ensures performance efficiency in all departments. This section acts as a connecting link between senior management and teachers. Besides, it motivates the workforce and ensures achieving organisational goals. When the educational institute's digital system is implemented, all employees must be familiar with and trained to use the same software and platforms. Such decisions are made by the senior management, who will ensure that all teachers are operating systematically.

Now that we have a clearer picture of what skills are needed for high competency at the educational institutes in Jordan, we need to research the degree of their availability in teachers and administrators of the Ministry of Education. Are such skills available? If so, to what degree?

Pratolo \& Solikhati, (2020) investigated digital literacy implementation in a private junior high school in Temanggung, identified teachers' attitudes in practising digital literacy and explored the challenges and coping mechanisms. They used a qualitative research method, where the interviews were conducted on a sample consisting of 10 teachers in the school. The results indicated that computers and smartphones were used as digital devices. In practice, teachers showed positive attitudes in terms of considering the syllabus as a core, understanding the teacher's position, developing effective learning, using multiple literacies and enhancing the four language skills. Meanwhile, lack of technology, students' background, lack of time and limited budgeting were obstacles in implementing digital literacy.

Gibbs, (2019) determined educators' beliefs about using technology in their classrooms and their digital literacy knowledge and suggested effective 
promotion tactics for professional development workshops. A mixed-methods approach has been used in the study, where an online questionnaire was distributed and interviews were conducted on a sample of 40 elementary (K-5) teachers and in Delaware County, Indiana. The results indicated that teachers need to acquire key digital literacy skills and feel comfortable teaching them before leaving the professional development course.

On the other hand, Yazon et al., (2019) determined the relationship between digital literacy, digital competence and educators' research productivity. They followed a descriptive correlational research design, where a questionnaire was distributed to a sample of 56 permanent faculty members at Laguna State Polytechnic University, Los Banos Campus. The results indicated a descriptive correlational and significant relationship between faculty members' digital literacy and productivity.

McGuinness \& Fulton, (2019) explored the role of the teacher's digital literacy (TDL) among other schools' digital literacy (SDC) components in determining the Digital Divide (DD) in Ghana's primary schools. The results indicated that the accessibility, ease-of-use, design and duration of tutorials were deemed effective in user engagement; however, several technological challenges were identified, such as browser incompatibility, uneven sound quality and general Internet connection issues, which disrupted the learning process.

Hosseini, (2018) examined teachers' perceptions about digital literacy instruction in early elementary school grades to identify existing obstacles to digital literacy education and support systems necessary to enhance instruction. A quantitative descriptive approach was used by distributing an online questionnaire to a sample of 37 kindergarten and first- and second-grade teachers in California. The results indicated that early elementary grade students in this school district are provided with more opportunities to practice computer literacy than information literacy skills. Teachers identified the high student-to-teacher ratio, lack of time to plan and teach technology lessons and limited self-management and independence skills as major impediments to digital literacy instruction in the early elementary grades. Conversely, they demonstrated that access to districtlevel technology coaches and on-site technical support, opportunities to observe demo technology lessons and their knowledge of grade-level technology standards enhance their ability to teach digital literacy skills.

Tewari \& Birla, (2018) examined the role of digital literacy of faculties on students' learning of various specialisations. They used a quantitative descriptive approach by distributing a questionnaire to a sample of 125 students from Denver Language School. The results indicated that students from different backgrounds would perceive the faculty's DL in their individualist way. The course (graduate and postgraduate) influences students' learning experience and understanding. Students in the current education scenario preferred the incorporation of digital technology and digital platforms in teaching pedagogy. 
Spante et al., (2018) established an understanding of referencing strategy to digital literacy and digital competence over time, disciplines, countries, methods and analysis levels. In this systematic literature review, three databases were used: Web of Science, Scopus and Education Resources Information Center. Initially, 107 publications between 1997 and 2017 were found, with 28 addressing digital competence and 79 digital literacy. The results indicated that future research in $\mathrm{HE}$ addresses digital literacy or digital competence needs to pay more attention to definitions' origin.

Furthermore, research needs to analyse how the different definitions might complement or contradict each other. It also becomes important to clarify the rationale for the preference of the specific selection of different definitions. Such clarifications facilitate understanding the research effort linked to investigating policy implementation or a more critical investigation linked to digital competence or digital literacy.

Çam \& Kiyici, (2017) identified digital literacy levels of prospective teachers in terms of several variables. Quantitative method was used where a questionnaire was distributed to a sample of 354 prospective teachers studying in different departments of Sakarya University College of Education. The results indicated that digital literacy levels were high in prospective male teachers (gender variable) and computer education and instructional technology teaching department (department variable). The research found that prospective teachers' income levels did not affect their digital literacy levels.

Kumari \& D'Souza, (2016) studied digital literacy levels among secondary school teachers in Mangaluru Taluk. They used a quantitative method by distributing a questionnaire to a sample of 73 teachers of private, aided and government schools of urban and rural areas across Mangaluru Taluk. The results indicated that digital literacy levels were average; the extent to which teachers in secondary schools use ICT was average; no significant difference was observed between the digital literacy level among teachers at secondary schools in urban and rural areas in Mangaluru Taluk.

Quaicoe \& Pata, (2015) identified the role of the teacher's digital literacy (TDL) among other schools' digital literacy (SDC) components in determining Digital Divide (DD) among Ghana's primary schools. They used a quantitative method where a questionnaire was distributed to a sample of 17 schools in urban, periurban and rural locations - randomly sampled from circuits in a metropolitan region of Ghana. The results indicated that DD in the sample schools was significantly influenced by TDL and ICT-related policy documents.

When the previous studies such as (Hosseini, 2018; Spante et al, 2018; Çam and Kiyici, 2017; Kumari and D'Souza, 2016) in the literature are observed, it has been detected that there are very few studies that focus on investigating digital literacy skills for the academic employees of the educational workplaces. Thus, this study is thought to be beneficial for the literature in terms of identifying the digital literacy skills and providing suggestions to enhance these skills. 


\section{Research Methodology}

\subsection{Research Goal}

The study investigates digital literacy skills and the degree of their availability among teachers and administrators of the Ministry of Education. The current study seeks to answer the following questions:

1. What are the digital literacy skills for teachers and administrators working in the Ministry of Education in Jordan?

2. What is the availability degree of digital literacy skills among teachers and administrators of the Ministry of Education in Jordan?

3. Is there a statistically significant difference in the availability of digital literacy skills for the Ministry of Education teachers and administrators due to job title and the educational workplace?

4. What is the effect of digital functional and informational skills on digital competence in teaching, learning, evaluating and empowering learners?

\subsection{Study Design}

This study follows a mixed methodology that combines quantitative and qualitative approaches to answer the above-mentioned questions. A qualitative approach is used to detect digital literacy skills by conceptual analysis (Gibbs, 2019). the researchers identified the four open-ended question and applied on the respondents, next they summarized and codded the answers text under each question into manageable content categories (Hosseini, 2018), and then detected the patterns(themes) which were the digital literacy skills for teachers and administrators. A quantitative (descriptive) approach is used to measure the degree of digital literacy availability. We measured the differences in digital literacy due to job title and workplace by using MANOVA. Correlation analysis was conducted to detect the relationship between digital functional and informational skills and digital competence.

\subsection{Participants}

The study population consisted of all teachers and administrators of the Ministry of Education in Jordan. The convenience sample consisted of 139 teachers and 73 administrators across 173 governmental sectors and 39 private sectors.

\subsection{Data Collection}

Two instruments were developed to collect data: an interview and a questionnaire. A semi-structured interview was developed for teachers and administrators of the Ministry of Education after reviewing the literature and previous digital literacy studies. The instrument contains all digital literacy skills summarised from the literature in addition to the open-ended question of what are the digital literacy skills that teachers and administrators should achieve? The participants will be asked in individual interviews with 15 experts to answer the open-ended question and whether they agree with the skills already included in this instrument as required skills for the study sample.

A questionnaire with a five-point Likert scale was developed according to the final digital literacy skills identified by the semi-structured interview to determine the degree of their availability in teachers and administrators of the Ministry of Education and differences in digital skills due to experiences, educational level 
and workplace. The questionnaires consisted of 40 skills categorised into four themes: digital functional skills (8 skills), digital informational skills (13 skills), digital competence in terms of teaching, learning and evaluation (11 skills) and digital competence in terms of empowering learners (8 skills).

\subsection{Validity and Reliability}

To check the first instrument's validity and reliability (individual interview), we composed the questions while consulting three academic leadership experts. The instrument's initial draft was presented to two professors in education specialising in digital literacy studies to be reviewed and get genuine feedback. The instrument was presented to teachers and administrators with more than ten years of experience, and feedback was taken for any improvements or adjustments. Experts in evaluation and measurements reviewed the instrument and checked the correlation between the interview questions and the study's questions. The instrument was presented to linguists to check the clarity of the questions. Five experts with more than ten years of experience in the educational field reviewed the list of digital literacy skills and open-ended questions. Then, the instrument was adjusted accordingly.

To check the content validity of the questionnaire, we presented in its initial form to several specialists in digital literacy studies to evaluate the questionnaire in terms of accuracy, comprehensiveness of the themes and the affiliation of paragraphs with each theme. The instrument was modified according to their observations.

The questionnaire was then applied to a pilot sample of 30 teachers and administrators of the Ministry of Education in Jordan that is different from the current sample. The instrument showed that Bartlett's test for Sphericity is significant at $\alpha=0.05$ and all eigenvalues are greater than one. Moreover, KMO value was greater than 0.5 (Hair et al., 2010), meaning that the instrument has enough validity to be used. The instrument's reliability was verified using Cronbach's alpha coefficient of 0.97 , which showed very good reliability (Pallant, 2005). Table 1 shows the correlation coefficient and Cronbach's alpha according to digital literacy skills.

Table 1: Constructive validity and reliability of digital literacy skills questionnaire

\begin{tabular}{|c|c|c|c|c|c|c|}
\hline \multirow[b]{2}{*}{ Creative thinking skill } & \multirow{2}{*}{ 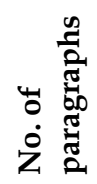 } & \multicolumn{4}{|l|}{ Validity } & \multirow{2}{*}{$\begin{array}{l}\text { Reliability } \\
\begin{array}{l}\text { Cronbach's } \\
\text { alpha }\end{array}\end{array}$} \\
\hline & & Eigenvalue & КМО & $\begin{array}{l}\text { Bartlett's } \\
\text { test for } \\
\text { Sphericity }\end{array}$ & Sig & \\
\hline Digital functional skills & 8 & 4.82 & 0.91 & 899.53 & $0.000^{*}$ & 0.91 \\
\hline $\begin{array}{l}\text { Digital informational } \\
\text { skills }\end{array}$ & 13 & 7.22 & 0.93 & 1650.48 & $0.000^{*}$ & 0.93 \\
\hline $\begin{array}{l}\text { Digital competence in } \\
\text { terms of teaching, } \\
\text { learning and evaluation }\end{array}$ & 11 & 4.58 & 0.93 & 1707.88 & $0.000^{*}$ & 0.94 \\
\hline $\begin{array}{l}\text { Digital competence in } \\
\text { terms of empowering } \\
\text { learners }\end{array}$ & 8 & 5.47 & 0.90 & 1270.64 & $0.000^{*}$ & 0.93 \\
\hline Overall & & & & & & 0.97 \\
\hline
\end{tabular}




\subsection{Analysis of Data}

- Kolmogorov-Smirnov test examined the normality distribution. The test showed that the sampled population is normally distributed with $\mathrm{D}(200)=0.083, \mathrm{P}=200$.

- $\quad$ Content analysis was used to find the in-demand digital literacy skills from the point of view of teachers and administrators of the Ministry of Education in Jordan.

- $\quad$ Frequencies, means, standard deviations and ranks were used to measure the degree of the availability of digital literacy skills in teachers and administrators of the Ministry of Education in Jordan.

- $\quad$ MANOVA was used to measure the differences in the degree of digital literacy skills in teachers and administrators of the Ministry of Education in Jordan attributed to the educational workplace, educational level and years of experiences.

- $\quad$ Correlation analysis was used to detect the relation between digital functional and informational skills and digital competence.

\section{Results and Discussion}

\subsection{Qualitative Results: The Digital Literacy Skills for Teachers and Administrators in the Educational Workplace}

The digital literacy skills survey was conducted by reviewing previous studies and then conducting an individual interview with specialists in educational technology to answer the open-ended question: What digital literacy skills should be available to teachers and administrative staff in the educational workplace in Jordan? After they provided the answers, the skills from the theoretical literature and the answers' content were analysed, resulting in general axes, domains, and items. The respondents divided the skills into two main axes, where the first is a requirement for the second, and each axis was divided into two subdomains. Figures 1-4 show the digital skills according to the designed model of the respondents' answers.

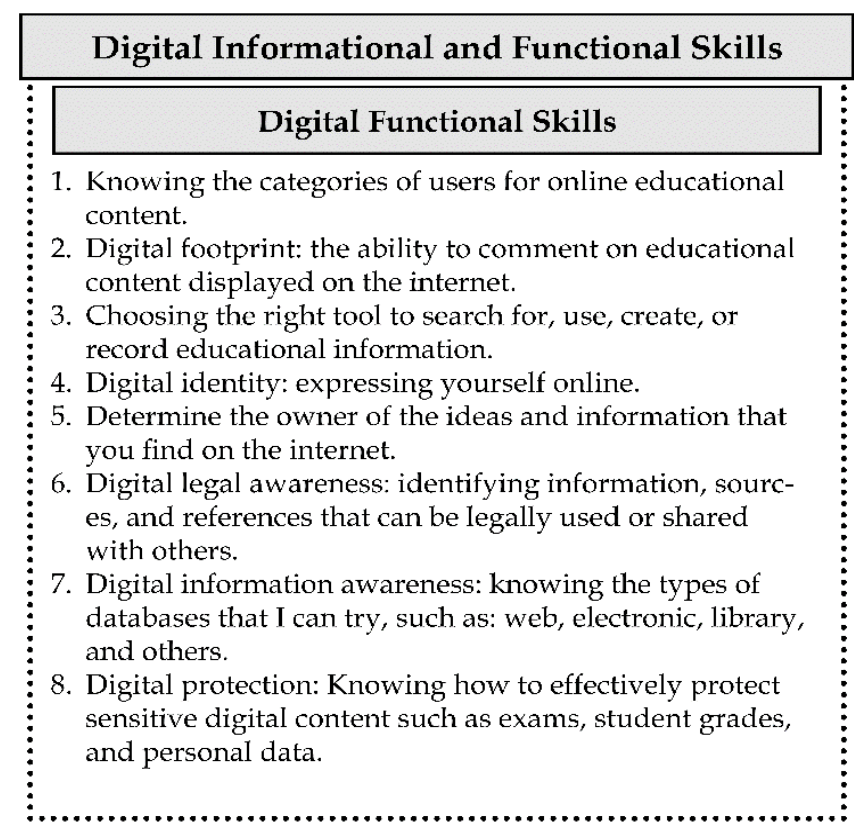

Figure 1: Digital functional skills 
Digital Informational and Functional Skills

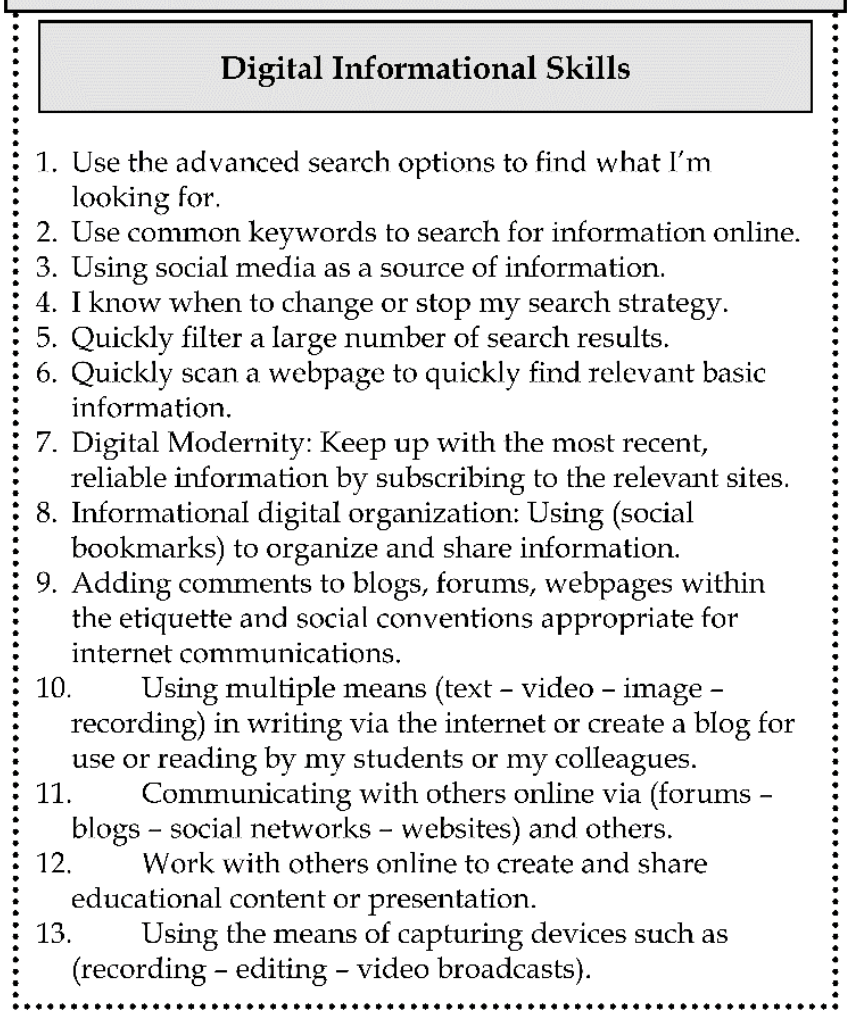

Figure 2: Digital informational skills

\begin{tabular}{|l|}
\hline \multicolumn{2}{|c|}{ Digital Competence } \\
\hline Digital Competence in Terms of Empowering Learners \\
1. When I create digital assignments for students, I consid- \\
er and address potential digital problems such as: equal \\
access to digital resources - problems of use - differenc- \\
es in digital skills. \\
2. I take into account digital individual differences by \\
using digital technologies that provide customized \\
educational opportunities, for example: giving different \\
students digital tasks that suit their individual learning \\
needs. \\
3. I use digital technologies to engage students in an activi- \\
ty in the classroom. \\
4. I train the students on how to assess the reliability of the \\
information and determine the information relevant to \\
the activity related to the subject. \\
5. I prepare assignments that require students to use digi- \\
tal means to communicate or collaborate with each other \\
or with an external audience. \\
6. I do homework that requires students to create digital \\
content such as video - audio - image - presentation, \\
blogs wikis. \\
7. I teach students about safe handling on the internet. \\
8. I encourage students to use digital technologies creative- \\
ly to solve concrete problems and overcome challenges \\
that limit the effectiveness of learning. \\
...........................................................................
\end{tabular}

Figure 3: Digital competence in terms of empowering learners 
Digital Competence

Digital Competence in Terms of Teaching, Learning, and
Evaluation

Figure 4: Digital competence in terms of teaching, learning, and evaluation

The results in figures (1-4) indicate that the digital literacy skills classify into four domains which are digital informational skills, digital functional skills, Digital competencies in empowering learners, and Digital competencies in LearningTeaching processing. The researchers attribute these classifications of digital literacy to the fact that educational technology experts understand the sequence of technological skills that any workers should learn to acquire the overall skills of digital literacy. Thus, workers become more aware of recent knowledge in digital literacy and how to employ it. This result is consistent with that by Tewari, S., and Birla, M (2018).

\subsection{Quantitative Results}

\subsubsection{The Degree of Availability of Digital Literacy Skills among Teachers and Administrators}

Table 2 shows that the fields' means ranged between 3.68 and 3.49 , with standard deviations of $0.84-0.72$. The value of the total arithmetic mean was 3.59 , with a standard deviation of 0.70 ; this indicates that the degree of availability of digital literacy skills among workers in Jordan's educational workplace was medium. 
Table 2. Means and standard deviations of the availability degree for the study themes

\begin{tabular}{|l|l|l|l|l|}
\hline Field & Mean & SD & Rank & $\begin{array}{l}\text { Availability } \\
\text { degree* }\end{array}$ \\
\hline Digital functional skills & 3.59 & 0.81 & 2 & Medium \\
\hline Informational digital literacy & 3.68 & 0.72 & 1 & Available \\
\hline $\begin{array}{l}\text { Digital competency in learning, } \\
\text { teaching and assessment }\end{array}$ & 3.57 & 0.76 & 3 & Medium \\
\hline $\begin{array}{l}\text { Digital competence in empowering } \\
\text { learners }\end{array}$ & 3.49 & 0.84 & 4 & Medium \\
\hline Overall & 3.59 & 0.70 & \multicolumn{2}{|l|}{ Medium } \\
\hline
\end{tabular}

Concerning digital functional skills, the values of the arithmetic averages were 3.72-3.42, with standard deviations of 1.11-0.98. The highest average was for the item "choosing the right tool to search for educational information and use it to create or record it" and the lowest average for the paragraph "digital information awareness: knowing the types of databases that can be conducted by information such as the electronic library web and others." We note that $88 \%$ of the skills were of medium availability and the overall arithmetic average for this field was 3.59 with a standard deviation of 0.81 with a medium degree, indicating that the degree of availability of digital functional skills among workers in the educational workplace in Jordan was medium.

For the field of information digital literacy, the arithmetic averages ranged were $4.05-3.19$, with standard deviations of $1.03-0.80$. The highest average was for the item "use common keywords to search for information via the Internet." The lowest average was for the paragraph "informational digital organisation: using the (social bookmark) to organise and share information." We note that $54 \%$ of the skills have been highly appreciated. In general, we note that this field's overall arithmetic means was 3.68 with a standard deviation of 0.72 , with a large degree, indicating the degree of availability of informational digital literacy among Jordan workers' educational workplace was available.

In the field of digital competence in the educational learning process, the values of the arithmetic averages were 3.73-3.41 with standard deviations of 1.01-0.92. The highest average was for the item "I use different websites and search strategies to find various digital resources, choose and adapt them to my needs." Furthermore, the lowest average was for the item "use digital technologies to allow students to plan, document and monitor their work such as self-assessment tests." We note that $90 \%$ of the skills was rated average. In general, the overall arithmetic average for this field was 3.57 with a standard deviation of 0.76 , with a medium degree, indicating that the degree of availability of digital competence in learning, teaching and evaluation among workers in the educational workplace in Jordan was medium. 
For digital competence in empowering learners, the values of arithmetic averages were 3.65-3.39 with standard deviations of 1.04-0.96 and a medium degree of availability. The highest average was for the paragraph "I encourage students to use digital technologies creatively to solve concrete problems and overcome obstacles and challenges that would reduce the effectiveness of learning" and that the lowest average for the item "I train students on how to assess the reliability of the information and determine the information related to the activity under study." A standard amount of 0.84 with a medium degree indicates that the degree of digital competence availability in empowering learners was medium.

The researchers attribute this result to the fact that the training courses that school staff, teachers and administrators take focus on the theoretical side of informational literacy and lack the functional and practical side of using this literacy.

The degree of availability of informational digital literacy among workers in the educational workplace in Jordan was large. The researchers attribute this result to the fact that informational digital literacy is widely spread among workers in Jordanian schools, as the Ministry of Education provides free courses to obtain the ICDL certificate, which provides them with many skills related to the Internet and information and digital literacy.

The results indicated that the degree of availability of digital competency in learning, teaching and evaluation among workers in educational workplaces in Jordan was medium, which could be because computer laboratories in schools are limited and unavailable, except for computer research teachers, and other teachers have no opportunity to use these laboratories. Lack of training on how to use the Internet and digital media in teaching, the curriculum length and lack of time due to the classroom's momentum do not enable the teacher to benefit from the Internet inside schools and constitute a barrier to employing digital skills.

The results indicated that the degree of availability of digital competence in empowering learners was medium because the training provided to Jordanian school personnel does not focus on employing these skills (such as taking into account individual differences and preparing assignments) in a digital environment.

These results are consistent with those in previous studies (Gibbs, 2019; Kumari \& D'Souza, 2016; McGuinness \& Fulton, 2019; Pratolo \& Solikhati, 2020) on the existence of informational digital literacy to a large extent with medium digital competence in learning, teaching and evaluation. Yazon et al., (2019) demonstrated the existence of high digital competence in learning, teaching and evaluation and the empowerment of learners.

\subsubsection{The Significant Difference in the Degree of Availability of Digital Literacy due to} Job Title and the Educational Workplace

In Table 3, apparent differences were observed in arithmetic mean values to the degree of availability of digital skills in general and each field between teachers and administrators. The table also shows apparent differences in the values of the 
averages of total availability and each field between workers in the public and private sectors. Multiple variance analysis was used to examine the substance of these differences and their statistical significance, as shown in Tables 4-5.

Table 3. Means and standard deviation of the availability degree according to job title and educational workplace

\begin{tabular}{|l|l|l|l|l|}
\hline \multirow{2}{*}{ Field } & \multicolumn{2}{|l|}{ Job title } & \multicolumn{2}{l|}{ Educational workplace } \\
\cline { 2 - 5 } & $\begin{array}{l}\text { Teacher } \\
\text { M(SD) }\end{array}$ & $\begin{array}{l}\text { Administrative } \\
\mathbf{M}(\mathrm{SD})\end{array}$ & $\begin{array}{l}\text { Public } \\
\text { sector } \\
\mathbf{M}(\mathrm{SD})\end{array}$ & $\begin{array}{l}\text { Private } \\
\text { sector } \\
\mathbf{M}(\mathrm{SD})\end{array}$ \\
\hline Functional digital skills & $3.44(0.77)$ & $3.87(0.79)$ & $3.51(0.83)$ & $3.91(0.62)$ \\
\hline $\begin{array}{l}\text { Informational digital } \\
\text { literacy }\end{array}$ & $3.56(0.71)$ & $3.90(0.69)$ & $3.64(0.75)$ & $3.84(0.54)$ \\
\hline $\begin{array}{l}\text { Digital competency in } \\
\text { learning, teaching and } \\
\text { assessment }\end{array}$ & $3.47(0.75)$ & $3.77(0.74)$ & $3.52(0.79)$ & $3.80(0.55)$ \\
\hline $\begin{array}{l}\text { Digital competence in } \\
\text { empowering learners }\end{array}$ & $3.41(0.80)$ & $3.64(0.89)$ & $3.64(0.86)$ & $3.61(0.72)$ \\
\hline The overall tool & $3.48(0.68)$ & $3.81(0.70)$ & $3.55(0.73)$ & $3.80(0.50)$ \\
\hline
\end{tabular}

The researchers attribute these results to the fact that administrators are keen to enrol in training courses to shift from teaching to management and achieve career development. Thus, they become more aware of recent developments in digital literacy and how to employ it. This result is consistent with that by Hosseini, (2018).

The results in Table 4 indicate that differences in the degree of availability of digital literacy skills according to job title were statistically significant at a level of $\alpha=0.05$, with all $p$ values being statistically significant $(0.05=\alpha)$. The difference was in favour of the administrative job title, where the arithmetic means were higher than those for the teachers.

Table 4. Differences significance in availability degree due to job title (MANOVA).

\begin{tabular}{|c|c|c|c|c|c|c|c|c|c|}
\hline \multirow[b]{2}{*}{ Theme } & \multicolumn{5}{|c|}{ Job title } & \multicolumn{2}{|l|}{ Error } & \multicolumn{2}{|l|}{ Macro } \\
\hline & 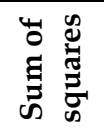 & df & 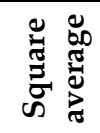 & $\mathbf{F}$ & Sig & 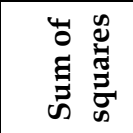 & $\mathrm{df}$ & 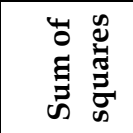 & df \\
\hline Functional digital skills & 9.184 & 1 & 9.184 & 15.097 & $0.00^{* *}$ & 103.325 & 210 & 136.929 & 211 \\
\hline $\begin{array}{l}\text { Digital information } \\
\text { literacy }\end{array}$ & 5.251 & 1 & 5.251 & 10.671 & $0.001^{* *}$ & 117.670 & 210 & 108.575 & 211 \\
\hline $\begin{array}{l}\text { Digital competency in } \\
\text { learning, teaching and } \\
\text { assessment }\end{array}$ & 4.325 & 1 & 4.325 & 7.719 & $0.006^{* *}$ & 145.005 & 210 & 121.995 & 211 \\
\hline $\begin{array}{l}\text { Digital competence in } \\
\text { empowering learners }\end{array}$ & 2.678 & 1 & 2.678 & 3.879 & $0.047^{* *}$ & 98.533 & 210 & 147.683 & 211 \\
\hline Overall & 5.063 & 1 & 5.063 & 10.790 & $0.001^{* *}$ & 103.325 & 210 & 103.596 & 211 \\
\hline
\end{tabular}


Table 5 shows that for the workplace variable, statistically significant differences were observed at the level of significance of $\alpha=0.05$ in the degree of availability of digital functional skills, digital competency in learning, teaching and evaluation and digital literacy skills in general. The value of $q$ was statistically significant at $\alpha=0.05$, and the difference was in favour of the private sector workplace, as the arithmetic means of their responses were higher than those for workers in the public sector.

Table 5. Differences significance in availability degree due to the educational workplace (MANOVA).

\begin{tabular}{|c|c|c|c|c|c|c|c|c|c|}
\hline \multirow[b]{2}{*}{ Theme } & \multicolumn{5}{|c|}{ Educational workplace } & \multicolumn{2}{|l|}{ Error } & \multicolumn{2}{|l|}{ Macro } \\
\hline & 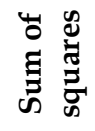 & df & 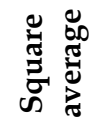 & $\mathbf{F}$ & Sig & 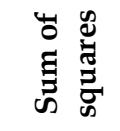 & df & 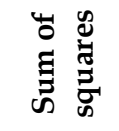 & df \\
\hline Functional digital skills & 4.923 & 1 & 4.923 & 7.833 & $0.006^{* *}$ & 132.005 & 210 & 136.929 & 211 \\
\hline $\begin{array}{l}\text { Digital information } \\
\text { literacy }\end{array}$ & 1.312 & 1 & 1.312 & 2.568 & 0.111 & 107.263 & 210 & 108.575 & 211 \\
\hline $\begin{array}{l}\text { Digital competency in } \\
\text { learning, teaching and } \\
\text { assessment }\end{array}$ & 2.436 & 1 & 2.436 & 4.279 & $0.040^{* *}$ & 119.559 & 210 & 121.995 & 211 \\
\hline $\begin{array}{l}\text { Digital competence in } \\
\text { empowering learners }\end{array}$ & 749 & 1 & 0.749 & 1.070 & 0.302 & 146.935 & 210 & 147.683 & 211 \\
\hline Overall & 2.011 & 1 & 2.011 & 4.158 & $0.043^{* *}$ & 101.584 & 210 & 103.596 & 211 \\
\hline
\end{tabular}

This conclusion agrees with a previous study where workers in the private sector were keener to possess and employ digital skills to maintain and advance their work. Simultaneously, public sector workers are more confident in job security and do not feel the need to develop in the digital field. These results are consistent with Hosseini's study (Hosseini, 2018) while conflicting with Kumari \& D'Souza, (2016).

\subsubsection{The Effect of Digital Functional and Informational Skills on Digital Competences}

Table 6 and Figure 5 shows that functional skills and digital informatics affect digital competence in learning, teaching, evaluation and empowerment of learners, with a correlation coefficient value of 0.791 , which indicates a high degree of correlation. The impact percentage reached $62.6 \%$ and this relationship is statistically acceptable, as the value of $\mathrm{P}$ was 351,404 with a significance level of 0.00 ; this value is statistically significant at the level of statistical significance of $=$ 0.05 .

Table 6. Simple linear regression of the relation between the axes of digital literacy skills

\begin{tabular}{|l|l|l|l|}
\hline Correlation coefficient (r) & Impact ratio (R2) & F & Sig \\
\hline 0.791 & 0.626 & 351.404 & 0.000 \\
\hline
\end{tabular}




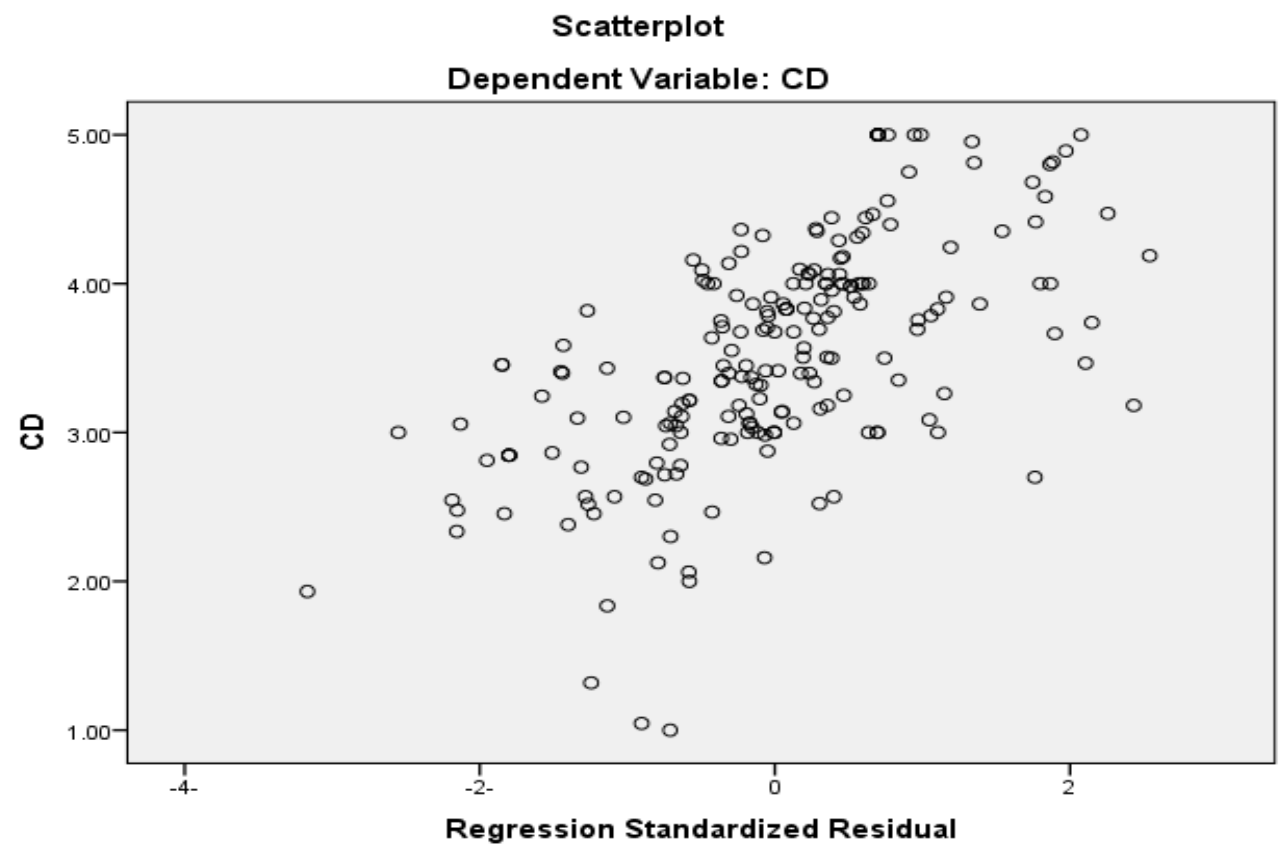

Figure 5: Scatterplot of Correlation between axes of digital literacy

Therefore, having functional and informational digital skills would make workers in the educational workplace more effective in communicating with students, colleagues and parents, thus more effective in the learning and teaching process. These skills also help students and direct them to perform their learning tasks using the necessary technologies, which led to students' empowerment and acquiring technical skills by exchanging technical expertise with their teachers.

\section{Conclusion}

This research was able to draw several conclusions based on the utilised two instruments and their results as follows. First, the degree of availability of digital literacy skills for workers in educational workplaces in Jordan was generally medium. Second, in educational workplaces, administrators have a higher digital literacy than teachers. Third, workers in the private educational workplace have higher digital literacy than those in the public sector. Fourth, functional and informational skills contribute to raising digital competence in learning, teaching, assessment and empowering learners.

\section{Recommendations}

- Train the academic employees of the educational workplaces on digital literacy skills and standards.

- To increase the investment and funds in digital literacy and development of digital infrastructure at the educational workplaces.

- To include digital literacy programs in the curriculum of higher learning institutions, taking into consideration that today's students, will be tomorrow's employees.

- To conduct future studies about digital literacy skills for students in different educational stages. 


\section{Acknowledgments}

The authors acknowledge the Middle East University, Amman, Jordan, for the financial support granted to cover this research article's publication fee.

\section{References}

Al-Omari, R. (2019). Statistical report for the academic year 2018/2019. Jordan: Ministry of Education.

Bhaumik, R. (2020). Most valued digital skills. https:/ / coursewareworld.com

Bortolazzo, S. F. (2020). Connections between Digital Culture and Education: Thinking the Digital Condition in Contemporary Society. ETD - Educação Temática Digital, 22(2), 369-388. https://doi.org/10.20396/etd.v22i2.8654547

Bosler, S., Pascau, J., Pleau, J., \& Fastrez, P. (2019). From concepts to the field: Digital culture in media literacy and media education. Communication Langages, No 201(3), 41-66. https://doi.org/10.3917/comla1.201.0041

Çam, E., \& Kiyici, M. (2017). Perceptions of Prospective Teachers on Digital Literacy. Malaysian Online Journal of Educational Technology, 5(4), 16.

Catalano, H. (2019). Opportunities and Challenges of Education in the Digital Age. Astra Salvensis, 14, 25-31.

Ehret, C., \& Čiklovan, L. (2020). How speculative designs produce new potentials for education research in digital culture. Discourse: Studies in the Cultural Politics of Education, 41(5), 708-722. https://doi.org/10.1080/01596306.2020.1774713

Gabriella, S. (2020). Digital Culture in basic Education: Uses of Public Policy Education in the Salvador Metropolitan region. Comunicologia: Revista Eletronica de Comunicacao e Epistemologia Da Universidade Catolica de Brasília (UCB), 13(1), 17-30.

Gibbs, A. (2019). Strategies for Digital Literacy Professional Development. Ball State University.

Hair, J. F., Black, W. C., Babin, B. J., Anderson, R. E., \& Tatham, R. L. (2010). Multivariate Data Analysis (7th ed.). Macmillan Publishing Company.

Hanafy, K. (2019). Our children in the era of digital culture. Islamic Consciousness, 56(651), 76-78.

Hosseini, D. (2018). Digital Literacy in Early Elementary School: Barriers and Support Systems in the Era of the Common Core. San Jose State University.

Kumar, N. A., \& Bhushan, S. (2020). Digital Culture - Evolving Context, Enduring Concepts And Everlasting Solutions. Journal of Services Research, 20(1), 39-56.

Kumari, V., \& D'Souza, F. (2016). Secondary School Teachers' Digital Literacy and Use of ICT in Teaching and Learning. International Journal of Computational Research and Development, 1(1), 141-146. https://doi.org/10.5281/zenodo.220927

Levy, L. A. (2018, July 25). Teacher Digital-Literacy. https://rossieronline.usc.edu

McGuinness, C., \& Fulton, C. (2019). Digital Literacy in Higher Education: A Case Study of Student Engagement with E-Tutorials Using Blended Learning. Journal of Information Technology Education: Innovations in Practice, 18, 001-028.

Pallant, J. (2005). SPSS survival manual: A Step-by-step guide to data analysis using SPSS for windows (Version 12) (2nd ed.). Open University Press.

Pettersson, F. (2018). On the issues of digital competence in educational contexts - a review of literature. Education and Information Technologies, 23(3), 1005-1021. https:// doi.org/10.1007/s10639-017-9649-3

Pratolo, B. W., \& Solikhati, H. A. (2020). The Implementation Of Digital Literacy In Indonesian Suburban EFL Classes. 9(01), 1-5.

Quaicoe, J. S., \& Pata, K. (2015). The Teachers' Digital Literacy: Determining Digital Divide in Public Basic Schools in Ghana. In S. Kurbanoglu, J. Boustany, S. Śpiranec, E. 
Grassian, D. Mizrachi, \& L. Roy (Eds.), Information Literacy: Moving Toward Sustainability (pp. 154-162). Springer International Publishing. https://doi.org/10.1007/978-3-319-28197-1_16

Spante, M., Hashemi, S. S., Lundin, M., \& Algers, A. (2018). Digital competence and digital literacy in higher education research: Systematic review of concept use. Cogent Education, 5(1), 1519143. https:// doi.org/10.1080/2331186X.2018.1519143

Tewari, S., \& Birla, M. (2018). Digital Literacy of Faculty \& Its Relationship with Teaching Learning: A Study on Student's Perspective. Pacific Business Review International, 11(6), 99-108.

The Higher Council for Science and Technology. (2010). Determining priorities for scientific research in Jordan for the years 2011-2020. Ammaan, Jordan.

UNICEF. (2017). UNICEF Annual Report 2017. https://www.unicef.org/reports/unicefannual-report-2017

Yazon, A. D., Ang-Manaig, K., Buama, C. A. C., \& Tesoro, J. F. B. (2019). Digital Literacy, Digital Competence and Research Productivity of Educators. Universal Journal of Educational Research, 7(8), 1734-1743. https://doi.org/10.13189/ujer.2019.070812

Yelubay, Y., Seri, L., Dzhussubaliyeva, D., \& Abdigapbarova, U. (2020). Developing Future Teachers' Digital Culture: Challenges and Perspectives. 2020 IEEE European Technology and Engineering Management Summit (E-TEMS), 1-6. https://doi.org/10.1109/E-TEMS46250.2020.9111827 